
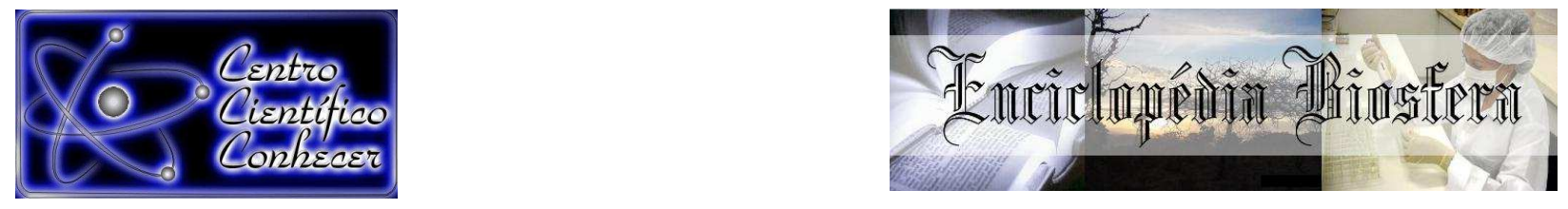

\title{
DESENVOLVIMENTO DE JUVENIS DO HÍBRIDO TAMBATINGA EM TANQUES- REDE COM DIFERENTES NÍVEIS DE PROTEÍNA NA RAÇÃO
}

Cleber Aparecido de Barros $^{1 *}$, Divina Sueide de Godoi $^{2}$, Auclar Felipe Botini $^{3}$, Luiz Antonio Jacyntho ${ }^{4}$, Jhonathan Ferreira Santos Maceno ${ }^{5}$

${ }^{1}$ Mestrando em Ambiente e Sistema de Produção Agrícola, UNEMAT, Tangará da Serra-MT, Brasil. "cleberapbarros@gmail.com

${ }^{2}$ Docente do Departamento de Ciências Biológicas, UNEMAT, Tangará da Serra-MT, Brasil.

${ }^{3}$ Mestrando em Genético e Melhoramento de plantas,UNEMAT, Tangará da SerraMT, Brasil.

${ }^{4}$ Docente do Departamento de Matemática, UNEMAT, Barra do Bugres-MT, Brasil.

${ }^{5}$ Discente do Curso de Ciências Biológicas, UNEMAT, Tangará da Serra-MT, Brasil.

Recebido em: 02/10/2017 - Aprovado em: 21/11/2017 - Publicado em: 05/12/2017 DOI: 10.18677/EnciBio_2017B20

Este trabalho avaliou o desempenho zootécnico de juvenis da espécie híbrida Tambatinga (C. macropomum $\times$ P. brachypomus) utilizando dois níveis diferentes de proteína bruta na ração (28 e $32 \%$ ), possibilitando assim apontar qual delas proporciona maiores ganhos produtivos do híbrido na região de Tangará da SerraMT. O experimento foi realizado na área experimental da Universidade do Estado de Mato Grosso (UNEMAT), no campus Tangará da Serra - MT no período de setembro a outubro de 2014 com duração de 45 dias. Foram utilizados 60 juvenis de Tambatinga (C. macropomum x $P$. brachypomus), distribuídos em seis tanques redes de $1 \mathrm{~m}^{3}$, instalados em um tanque escavado na densidade de 10 juvenis $/ \mathrm{m}^{3}$. $\mathrm{O}$ delineamento experimental utilizado foi blocos ao acaso, com dois tratamentos (tratamento 1 ração com $28 \%$ proteína bruta, tratamento 2, 32\% proteína bruta), com três repetições, sendo que cada unidade experimental foi composta por três tanques redes. Os resultados apontaram que os juvenis da espécie híbrida alimentados com ração de $32 \%$ de proteína bruta, apresentaram melhor conversão alimentar e menor consumo de ração, já os alimentados com $28 \%$ obtiveram maior ganho de peso e biomassa final. Sendo assim a ração com $32 \%$ de proteína bruta mostrou-se superior a ração com $28 \%$ de proteína.

PALAVRAS- CHAVE: Conversão alimentar, Índice zootécnico, Peixe.

\section{YOUTH DEVELOPMENT OF HYBRID TAMBATINGA TANKS IN-NETWORK WITH DIFFERENT LEVELS IN PROTEIN FEED}

\footnotetext{
ABSTRACT

This study evaluated the growth performance of juvenile of Tambatinga hybrid species (C. macropomum $\times$ P. brachypomus) using two different levels of crude protein in the diet (28 and $32 \%$ ), thus enabling point which one brings greater production of hybrid gains in the region of Tangara da Serra-MT. The experiment
} 
was conducted in the experimental field of Universidade do Estado de Mato Grosso in the fish farming industry ichthyology laboratory and fish farming (LIP) in the period from September to October 2014 with duration of 45 days. 60 juvenile Tambatinga were used (C. macropomum $\times$ P. brachypomus), distributed in six tanks networks $1 \mathrm{~m}^{3}$, installed in a tank dug in the density of 10 juveniles $/ \mathrm{m}^{3}$. The experimental design was a randomized block design, with two treatments (treatment 1 ration with $28 \%$ crude protein, treatment $232 \%$ crude protein) with three replications, and each trial unit consisted of three tanks networks. After the period of 45 days, it was determined survival rate (S\%), weight gain (GPM) daily weight gain (ADG), gain mean biomass (GBM) and feed conversion (FC). The results showed that the youth of hybrid species fed $32 \%$ crude protein feed, showed better feed conversion and lower feed intake, since the fed $28 \%$ had greater weight gain and end biomass. Thus the ration with $32 \%$ crude protein was superior to feed with $28 \%$ protein.

KEYWORDS: Fish, feed conversion, livestock index.

\section{INTRODUÇÃO}

A aquicultura tem crescido a cada ano no Brasil, esta atividade vem conquistando rapidamente espaço, muitas vezes substituindo outras tidas como tradicionais, como a pecuária e a agricultura, dentre outras (SAMPAIO et al., 2013). A produção mundial de peixes apresentou crescimento extremamente acentuado na última década, consolidando-se como um setor de grande importância econômica e participando de maneira significativa no suprimento das necessidades proteicas da humanidade, a produção total de peixes da piscicultura brasileira foi de 483,24 mil toneladas em 2015, um aumento de $1,5 \%$ em relação ao ano anterior (FAO/ONU, 2016).

O grande potencial hídrico do Brasil, bem como as condições climáticas características da região tropical que permitem o rápido crescimento de várias espécies de peixes nativos, a piscicultura tem ganhado destaque na aquicultura. (IBGE, 2015). Mato Grosso apresenta amplo potencial de crescimento da atividade de piscicultura pela alta disponibilidade de produtos para a indústria de ração, abundância de água doce, clima favorável e alta demanda do consumo tanto interno como externo do Estado. Diante dessa riqueza de recursos naturais presentes no âmbito do território estadual, é preciso diversificar a matriz produtiva do estado para o abastecimento do mercado interno. Neste contexto, a piscicultura se apresenta como uma das alternativas para os produtores rurais aumentarem o portfólio de produtos dentro de suas fazendas para o aumento da lucratividade rural (IMEA, 2014).

Com o aumento da produção surge também a necessidade de pesquisas sobre comportamento, espécies adequadas para criação, taxa de crescimento, sanidade, nutrição, melhoramento genético, entre outros, tornando a piscicultura cada vez mais lucrativa e produtiva no país. Diante de um imenso potencial piscícola, torna-se necessário melhorar as condições do ambiente e o manejo alimentar (SILVA et al., 2016). A obtenção de peixes com melhor ganho de peso, conversão alimentar e rendimento de carcaça é o objetivo de todo piscicultor.

Conhecendo os índices zootécnicos de cada espécie é possível melhorar o desenvolvimento dos peixes e evitar gastos excessivos na produção. Entre os peixes híbridos, destaca-se a Tambatinga produzido a partir do cruzamento da fêmea de tambaqui (Colossoma macropomum) com o macho de Pirapitinga (Piaractus brachypomus), o qual apresenta superioridade em relação as suas 
espécies parentais quanto ao crescimento e produtividade (HASHIMOTO et al, 2012; DIAS et al., 2012).

O C. macropomum conhecido popularmente como Tambaqui exclusivo da bacia amazônica, no meio natural alcança um peso máximo de aproximadamente 30 $\mathrm{kg}$, em cultivos, pode chegar a um $\mathrm{kg}$ no primeiro ano, 1,5 a $3 \mathrm{~kg}$ no segundo, é um dos peixes mais apreciados da culinária amazônica e amplamente aceito em outras regiões (BRASIL, 2010).

O $P$. brachypomus conhecido como Pirapitinga, com registros na bacia amazônica, do Prata e do Tocantins é outra espécie muito cultivada, possui coloração cinza arroxeado uniforme, nos adultos, e cinza claro, com manchas alaranjadas, nos jovens o dorso é escuro e pode alcançar até $80 \mathrm{~cm}$ de comprimento e cerca de $20 \mathrm{Kg}$ de peso, em cultivo pode chegar a um $\mathrm{kg}$ já no primeiro ano (PESSOA, 2009). Ambos pertencem a ordem Characiformes, família Characidae e subfamília Serrasalminae (VÁSQUEZ-TORRES, 2005; GRAÇA ; PAVANELLI, 2007).

Há uma variante na exigência nutricional entre as duas espécies, fazem-se necessários estudos que avaliem as exigências nutricionais da espécie híbrida Tambatinga (C. macropomum x P. brachypomus). Araripe et al., (2011) concluíram que a espécie se desenvolveu de maneira satisfatória com $28 \%$ de proteína bruta na ração na região norte do país, mas foi necessária uma suplementação com aminoácidos.

Este trabalho avaliou o desempenho zootécnico em juvenis da espécie hibrida Tambatinga ( $C$. macropomum $\times$ P. brachypomus), utilizando dois níveis diferentes de proteína bruta na ração (28 e 32 \%), na região de Tangará da Serra, Estado de Mato Grosso.

\section{MATERIAL E MÉTODOS}

\section{Área de Estudo}

O experimento foi realizado na área experimental da Universidade do Estado de Mato Grosso (UNEMAT), no campus Tangará da Serra - MT, em agosto a outubro de 2014. A média anual de temperatura do município precipitação e umidade relativa do ar foram, respectivamente: $24,4^{\circ} \mathrm{C}, 1.500 \mathrm{~mm}$ e $70-80 \%$ (MARCO et al., 2014).

Os tanques-rede foram implantado em um viveiro escavado, que apresenta renovação $5 \mathrm{~L} / \mathrm{s}$ e as medidas são, 40 metros de comprimento, 25 metros de largura e um metro e 90 centímetros de profundidade.

\section{Animais}

Os alevinos utilizados nesta pesquisa foram da espécie híbrida Tambatinga (Colossoma macropomum, fêmea $x$ Piaractus brachypomus, macho), na densidade de 10 peixes $/ \mathrm{m}^{3}$ distribuídos aleatoriamente com tamanhos e pesos diferentes em seis tanques-rede perfazendo um total de 60 peixes.

\section{Viveiros}

Foram instalados seis tanques-rede de $1 \mathrm{~m}^{3}$ (Figura 1), confeccionados com tela galvanizada com malha de $13 \mathrm{~mm}$, fixadas em estrutura de madeira. Nas laterais, utilizaram-se galões de cinco litros para flutuação e um alimentador usando placas de plástico, para a ração permanecer na gaiola. 


\section{Tratamentos e delineamento experimental}

$O$ delineamento experimental foi inteiramente casualizado, com dois tratamentos com três tanques-rede cada, distribuídos aleatoriamente com alevinos de tamanhos e pesos diferentes. O experimento foi feito com duas rações comerciais extrusadas, sendo Tratamento 1 (T1) com ração $28 \%$ de proteína bruta (PB), com tamanho dos grãos de 4 a $6 \mathrm{~mm}$ e Tratamento 2 (T2) com ração $32 \%$ de proteína bruta, com tamanho de 4 a $6 \mathrm{~mm}$.

\section{Biometria}

Para realizar a medição, foram utilizadas réguas com medidas de comprimento padrão, graduada em milímetros e para a obtenção das medidas de massa corporal, balança digital com precisão de $1 \mathrm{~kg}$. Todos os dados foram coletados no início do experimento e depois a cada 15 dias até o término de 45 dias. O ganho de peso foi determinado pela diferença entre o peso médio final e o peso médio inicial dos juvenis de cada tratamento.

\section{Alimentação}

Os peixes foram alimentados com ração comercial duas vezes ao dia (manhã às 08:00 e tarde as 16:00). $O$ fornecimento de ração foi realizado com base na porcentagem da biomassa (5\% de peso vivo convertido em gramas de ração), os reajustes da quantidade ocorreram através de biometrias quinzenais.

\section{Variáveis de desempenho produtivo}

Ao fim do experimento foram usadas as seguintes equações: taxa de sobrevivência (S\%), ganho de peso médio diário (GPMD), ganho de peso médio (GPM), o ganho de biomassa média (GBM) e conversão alimentar (CA), segundo propuseram Botini et al. (2015).

Qualidade da água dos viveiros Os dados estatísticos obtidos foram submetidos ao teste bilateral de kolmogorov-Smirnov para verificar a normalidade, usando a análise de variância ANOVA, submetida a um critério, utilizando teste de Tukey, com o programa Bioestat, versão 5.3, que pode ser obtido gratuitamente pelo site http://www.mamiraua.org.br/pt-br/downloads/programas/.

Para mensurar os paramêtros físico-químicos foram utilizados o aparelho HORIBA LAQUA modelo $75 \mathrm{G}$, durante todo a pesquisa, sendo médido no périodo matutino e vespertino.

\section{RESULTADOS E DISCUSSÃO}

\section{Qualidade da água}

A temperatura média no horário matutino $(8 \mathrm{~h})$ foi de $26,4{ }^{\circ} \mathrm{C}$ e no horário vespertino $(17 \mathrm{~h})$ foi de $29,4{ }^{\circ} \mathrm{C}$. Utilizando-se todas as medidas diárias, a temperatura média geral foi de $27,9{ }^{\circ} \mathrm{C}$, sendo que a menor medida foi $26^{\circ} \mathrm{C}$ e a maior $30^{\circ} \mathrm{C}$, que pode ser considerada uma ótima faixa para o desenvolvimento do híbrido (Figura 2). Leira et al., (2017), afirmam que peixes oriundos de regiões tropicais são chamados peixes de águas quentes, e que a faixa ótima para crescimento é entre 24 e $28^{\circ} \mathrm{C}$. Kubitza, (1998) diz que a temperatura ideal para o cultivo da espécie hibrida Tambatinga é de 28 a $30 \stackrel{\circ}{\circ}$.

Os efeitos negativos da qualidade de água podem resultar em prejuízo ao 
crescimento, reprodução, sanidade, sobrevivência e qualidade dos peixes. A água na aquicultura é uma fonte importantíssima, mantê-la com qualidade ajuda o produtor a obter ótimos resultados na produção (MACEDO; SIPAÚBA-TAVARES, 2010).

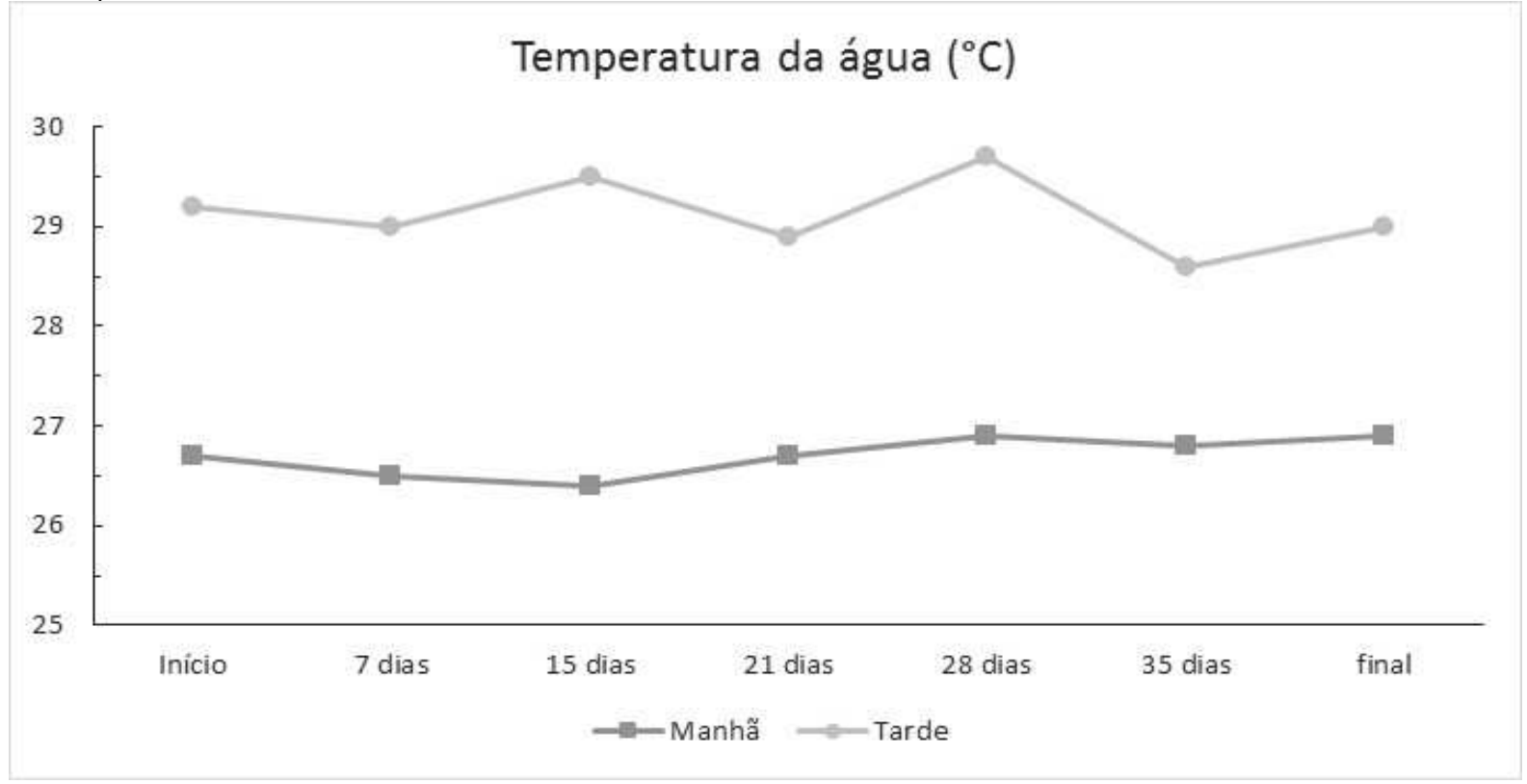

FIGURA 1. Temperaturas da água ${ }^{\circ} \mathrm{C}$, registradas pela manhã e à tarde durante $\mathrm{o}$ período experimental.

Os valores de $\mathrm{pH}$ comprovaram não ocorrer alterações severas no período de estudo, resgistrando $\mathrm{pH}$ médio de 6,98 (Figura 2), este valor encontra-se dentro da faixa recomendada para a espécie, 6,5 a 9,0 (BALDISSEROTTO; GOMES, 2005). Esteves (2011) enfatiza que o pH é uma das variáveis principais para os organismos aquáticos, sendo um dos mais complexos de interpretar porque vários fatores externos ou internos podem causar sua alteração.

Este resultado era esperado, já que foi realizada a calagem na preparação do viveiro e segundo Faria et al., (2013), este procedimento além de equilibrar o pH, visa a melhoria da produtividade e dos índices de sustentabilidade ambiental, pois tem como objetivos neutralizar a camada superficial de sedimentos do fundo dos viveiros e aumentar a alcalinidade total e a dureza total da água.

A acidez do sedimento do fundo dos viveiros deve ser corrigida até atingir valores entre 7,0 e 8,0 e as concentrações da alcalinidade total e dureza total da água devem ser elevadas acima de $20 \mathrm{mg} / \mathrm{L}$ (LIMA et al., 2013). A utilização de adubos orgânicos e a calagem dos viveiros suprem o fitoplâncton com gás carbônico para a fotossíntese gerando um aumento na produção de oxigênio (TAVARES, 2013). 


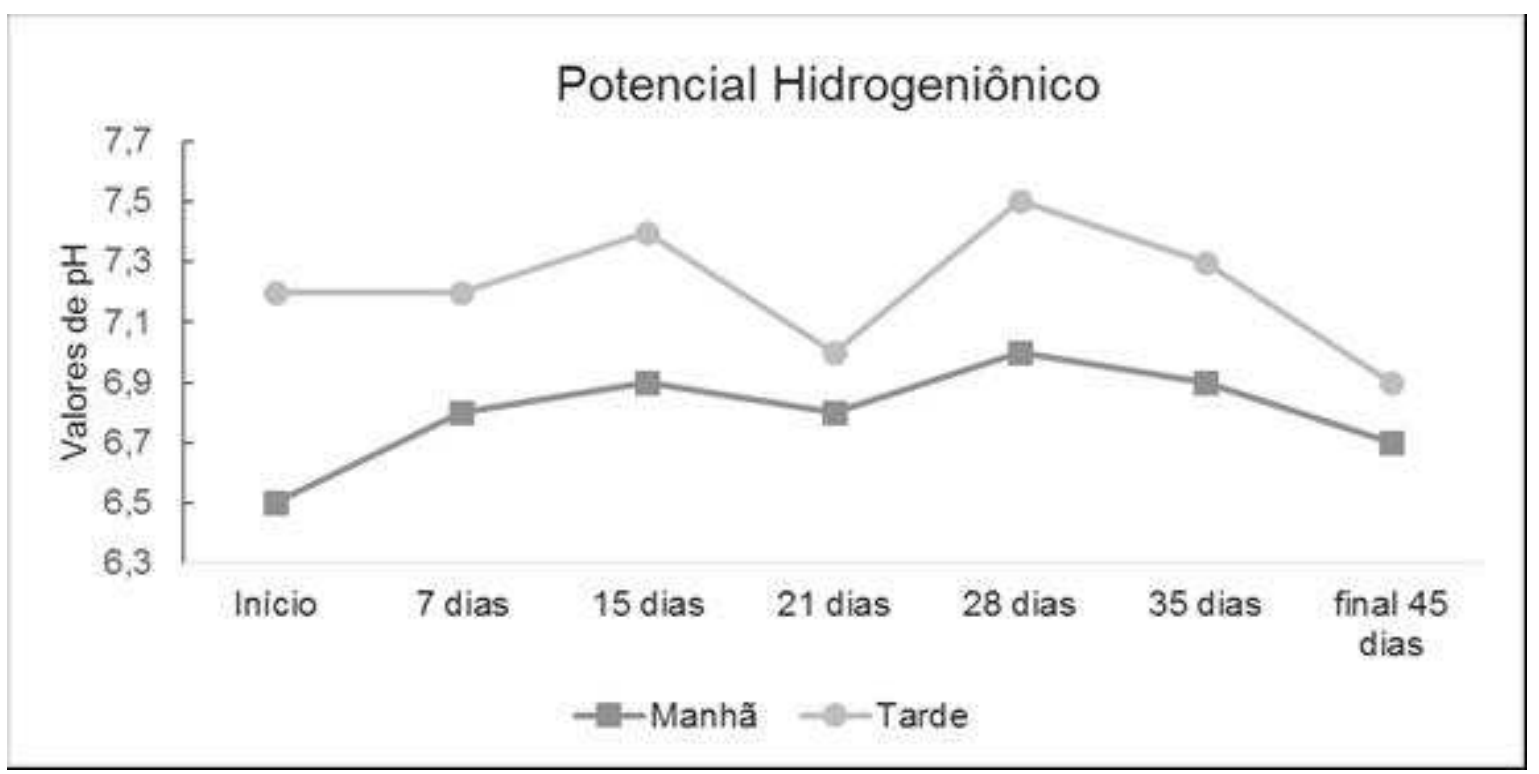

FIGURA 2. Valores de $\mathrm{pH}$ da água do viveiro escavado durante o período experimental.

o oxigênio dissolvido (OD) médio ficou em torno de $5,4 \mathrm{mg} / \mathrm{L}$ (Figura 3). $\mathrm{O}$ OD é o fator do meio mais limitante num sistema intensivo. Em Cyrino et al., (2010) é possível verificar que em geral, concentrações de OD mais que $5 \mathrm{mg} / \mathrm{L}$ são adequadas à produção de peixes tropicais, já Tavares (2013) indica $4 \mathrm{mg} / \mathrm{L}$, o que mostra que os números médios de OD na realização do trabalho, permaneceu na faixa do ideal, já que trata-se de peixe oriundo de regiões tropicais.

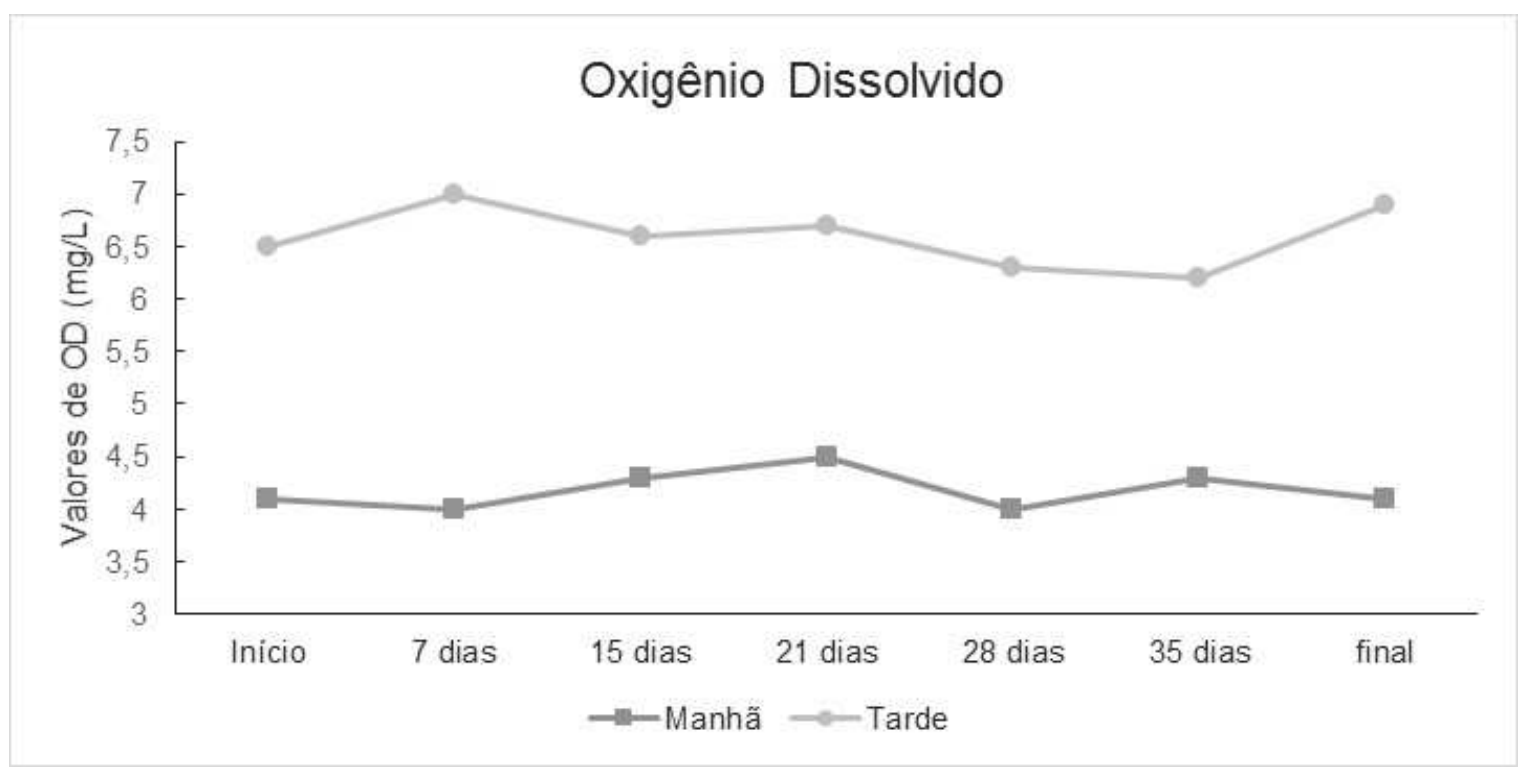

FIGURA 3. Oxigênio Dissolvido $\mathrm{mg} / \mathrm{L}$, da água do viveiro escavado, durante o período experimental.

\section{Desempenho produtivo}

A taxa de sobrevivência do híbrido foi de $100 \%$ (Tabela 1), não houveram óbitos e nem ataque de predadores durante o experimento, este resultado se apresenta superior à média obtida para a Tambatinga nos sistemas de viveiro $(75 \%)$ 
e em tanques redes apresentadas por outros autores (94\%) (SOUZA et al.,1998; MELO et al., 2001).

O crescimento é um fator que expressa a velocidade com a qual os peixes ganham peso em um determinado tempo. O desempenho é caracterizado por registros realizados ao longo de todo o cultivo, através de índices referentes ao peso, ganho de peso e conversão alimentar (OSTRENSKY; BOEGER, 1998).

TABELA 1. Médias dos Resultados das Análises Biométricas T1 (Tratamento 1) T2 (Tratamento 2).

\begin{tabular}{l|c|c}
\hline & \multicolumn{2}{c}{ TRATAMENTOS } \\
& T1 (28\%) & T2 (32\%) \\
\hline Número inicial de peixes & 30 & 30 \\
\hline Peso inicial $(\mathrm{g})$ & 34,05 & 36,31 \\
\hline Peso final $(\mathrm{g})$ & 115.7567 & 112.8233 \\
\hline Comprimento inicial $(\mathrm{cm})$ & 10,29 & 10,35 \\
\hline Comprimento final $(\mathrm{cm})$ & 14,45 & 14,32 \\
\hline Biomassa inicial $(\mathrm{g})$ & 1021,5 & 1089,3 \\
\hline Biomassa final $(\mathrm{g})$ & 3453,9 & 3246 \\
\hline Ganho de Biomassa (g) & 2432,4 & 2156,7 \\
\hline Ganho de peso médio diário $(\mathrm{g}$ & 1,80 & 1,60 \\
\hline dia) & 30 & 30 \\
\hline Número final de peixes & $1.7: 1$ & $1.6: 1$ \\
Conversão alimentar & & \\
\hline
\end{tabular}

Para realizar testes estatísticos referentes a característica do peso dos híbridos, inicialmente foi necessário saber se cada lote podia ser representado por uma distribuição normal. Com isso, após obter os valores dos pesos finais os mesmos foram submetidos ao teste bilateral de kolmogorov-Smirnov para a verificação da distribuição. Para os híbridos que foram alimentados com ração $28 \%$ denominados Tanque 1 ( $\mathrm{Tq} 1$ ), Tq 3 e Tq 5, os resultados foram os seguintes: para Tq1 o valor calculado para $D$ foi de 0,1376 e o valor crítico bilateral $(0,05)$ foi 0,409 , não houveram evidências suficientes para rejeitar a hipótese de que a distribuição foi normal. O mesmo pode-se concluir para Tq3 e Tq5, que apresentaram respectivamente $D=0,2243$ com valor crítico bilateral $(0,05)$ igual a 0,409 e $D=$ 0,1435 com valor crítico bilateral $(0,05)$ igual a 0,409.

Para os híbridos que foram alimentados com ração $32 \%$ denominados Tq2, Tq4 e Tq6, os resultados foram os seguintes: para Tq2 o valor calculado para $D$ foi de 0,4025 e o valor crítico bilateral $(0,05)$ foi 0,409 , não houveram evidências suficientes para rejeitar a hipótese de que a distribuição foi normal. O mesmo podese concluir para Tq4 e Tq6, que apresentaram respectivamente $D=0.1295$ com valor crítico bilateral $(0,05)$ igual a 0,409 e $D=0.4003$ com valor crítico bilateral $(0,05)$ igual a 0,409.

Foi feita também uma verificação de normalidade com todos os valores de T1 agrupados em uma amostra que apresentou $D=0.1639$ e valor crítico bilateral $(0,05)$ igual a 0.242 , indicado assim uma normalidade para estes dados. Para todos os valores de T2, que também foi feito o mesmo procedimento e o valor determinado para D foi de 0.2012 , com valor crítico bilateral $(0,05)$ igual a 0.2420 , podendo 
concluir que não existiram evidências para negar que apresenta distribuição normal.

Como foi verificada a normalidade para pesos finais de T1 e T2, foi realizada à análise de variância um critério utilizando teste de Tukey, e conforme tabela 2, verificou-se diferença significativa entre as médias de pesos finais entre T1 e T2 com $\mathrm{p}<0.05$.

TABELA 2. Anova um critério teste de Tukey para os pesos finais de T1 e T2.

\begin{tabular}{l|r|r|r}
\hline FONTES DE VARIAÇÃO & GL & SQ & QM \\
\hline Tratamentos & 1 & 129.067 & 129.067 \\
\hline Erro & 58 & $13.0 \mathrm{e}+02$ & 22.334 \\
\hline $\mathrm{F}=$ & & & \\
\hline (p) $=$ & 5.779 & & \\
\hline Média (Coluna 1) $=32 \% \mathrm{~Pb}$ & 112.8233 & & \\
\hline Média (Coluna 2) $=28 \% \mathrm{~Pb}$ & 115.7567 & & \\
\hline & & & \\
\hline Tukey: & Diferença & $\mathrm{Q}$ & $(\mathrm{p})$ \\
\hline Médias (1 a 2) $=$ & 2.9333 & 3.3997 & $<0.05$ \\
\hline
\end{tabular}

Os pesos médios verificados após 45 dias foram de $115.7567 \mathrm{~g}$ no T1 e $112.8233 \mathrm{~g}$ para T2, demonstrando maior ganho de peso no $\mathrm{T} 1$, esse ganho resultou em diferenças entre os tratamentos (tabela 1), demonstrando que os animais alimentados com a ração de $28 \%$ PB (T1) ganharam mais peso g/dia, porém 0 consumindo mais, o que gera desvantagem sobre T2 que embora tenha gerado menos peso $\mathrm{g} /$ dia consumiu menos ração e apresentou resultado semelhante aos verificados por Melo et al. (2001) (1,69 g/dia), e superior ao apresentado por Paula (2009) $(0,96 \mathrm{~g} / \mathrm{dia})$.

Este bom desempenho está correlacionado a capacidade alimentar da Tamgatinga, porque são eficientes no processo de filtragem do plâncton existente no meio, justamente por possuir maior número de rastros branquiais que a Pirapitinga (PORTO-FORESTI et al., 2011). Segundo Kubitza (1999), o plâncton é formado por microrganismos com altas taxas proteícas, presentes abundantemente na água dos viveiros, o que auxiliar na engorda desses peixes.

A conversão alimentar (CA) apresentou diferenças entre T1 e T2 (Tabela 1), com destaque para o T2 que demostrou vantagem sobre o T1, com melhores taxas de CA e ganho compensatório, pois pode melhorar a taxa de produtividade, trazendo diferença em um período maior de tempo para o piscicultor, já que o peixe convertendo mais diminui o consumo de ração o que consequentemente diminui os custos de produção gerando maior ganho econômico para o produtor.

Conforme Kubitza (2011), as rações podem compor $40 \%$ a $70 \%$ do custo de produção, representando o principal item de custo na piscicultura intensiva, afirma ainda que uma das maneiras mais eficazes dos produtores minimizarem este custo é ajustar adequadamente a qualidade das rações e o manejo alimentar. $O$ uso de rações balanceadas e de boa qualidade é fundamental para o alcance de altas taxas de produtividade, em função da melhoria da CA. Adicionalmente, rações de boa qualidade proporcionam alta digestibilidade, o que contribui para reduzir 0 lançamento de efluentes no meio ambiente (SIDONIO et al., 2012). 


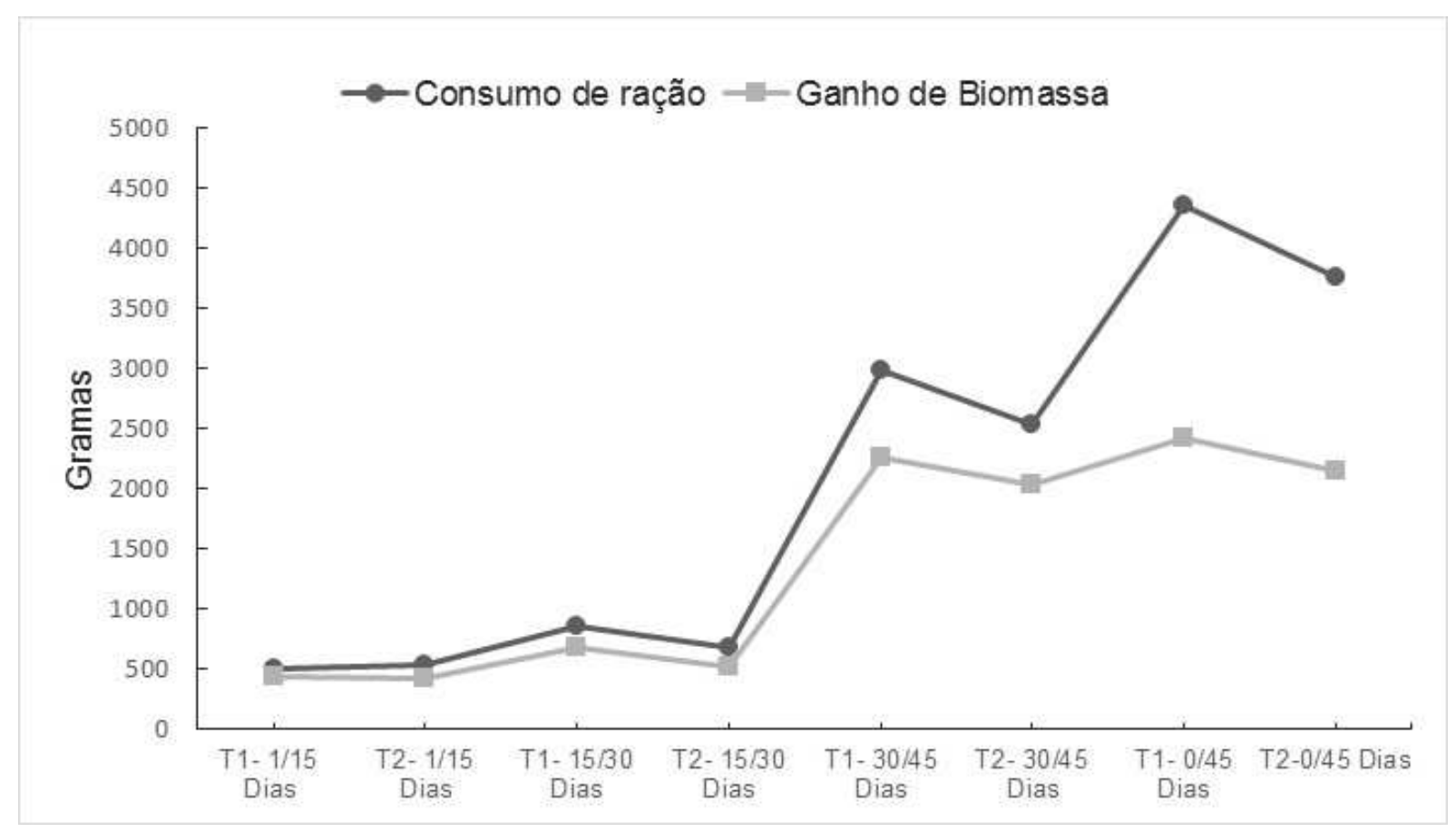

FIGURA 4 Comparativo entre consumo de ração e biomassa.

A biomassa final apresentou diferença significativa $(p<0,05)$, com o T1 apresentando maior índice final (tabela 1), porém ao ser comparado com o consumo de ração, o T2 mesmo apresentando menor biomassa final torna-se mais lucrativo, pois gerou menos custos e um peixe magro de melhor qualidade (Figura 4). Segundo Santos et al., (2010) o acúmulo de grandes quantidades de gordura corporal em tambaquis alimentados com dietas com baixos teores de proteína têm sido reportados por pesquisadores.

O consumo de ração final apresentou diferenças significativas $(p<0,05)$, com vantagem para o T2 que consumiu menos, pois obteve uma CA mais eficiente. Resultado semelhante ao de Santos et al., (2010) que concluíram que os peixes que se alimentaram com a ração com $32 \%$ de proteína bruta conseguiram ter melhor aproveitamento proteico com menor consumo.

\section{CONCLUSÃO}

Os resultados demonstraram que os alevinos de Tambatinga apresentaram maiores ganhos de produtividade com a ração de $32 \%$ PB, quando que comparados com de $28 \% \mathrm{~PB}$, já que os peixes consumiram quantidades menores de ração e obtiveram conversão alimentar satisfatório, minimizando o custo da produção inicial.

A produção de Tambatinga em tanques-rede mostrou-se eficaz para piscicultura na região de Tangará da Serra-MT, quando alimentada com a quantidade de proteína ideal para sua fase inicial.

\section{REFERÊNCIAS}

ARARIPE, M. N. B. A.; ARARIPE, H. G. A.; LOPES, J. B.; CASTRO, P. L.; BRAGA, T. E. A.; FERREIRA, A. H. C.; ABREU, M. L. T. Redução da proteína bruta com 
suplementação de aminoácidos em rações para alevinos de tambatinga. Revista Brasileira de Zootecnia, v.40, n.9 ,Viçosa Sept. 2011.

BALDISSEROTTO, B.; GOMES, L. C. Espécies natives para piscicultura no Brasil. Santa Maria: Editora UFMS, 2005, 470p.

BOTINI, A. F.; BARROS, C. A.; SOUZA, H. T.; BOTINI, N.; GODOI, D. S. Desenvolvimento de juvenis de híbrido "cachadia" (Pseudoplatystoma reticulatum fêmea $x$ Leiarius marmoratus macho) em tanques-rede, com diferentes níveis de proteínas na ração. Enciclopédia biosfera, Goiânia, v.11 n. 22, p 905-921, 2015.

BRASIL B. Ministério da Pesca e Aquicultura. Boletim estatístico da pesca e aquicultura- Brasil 2010. Brasília, 2012. Disponível em: <http://www.mpa.gov.br/images/Docs/Informacoes_e_Estatisticas/BoletimEstatistico MPA2010.pdf>. Acesso em: 20 ago. 2014.

CYRINO, J. E. P.; BICUDO, A. J. A.; SADO, R. Y.; BORGHESI, R.; DAIRIKI, J. K. A piscicultura e o ambiente - o uso de alimentos ambientalmente corretos em piscicultura. Revista Brasileira de Zootecnia, v.39, n.(Suplemento), p.68 - 87, 2010.

DIAS, M. K. R.; TAVARES-DIAS, M.; MARCHIORI, N. first report of Linguadactyloides brinkmanni (monogenoidea: linguadactyloidinae) on hybrids of Colossoma macropomum x Piaractus brachypomus (characidae) is de $100 \%$ até 2025. Disponível em http://www.fao.org/brasil/noticias/detailevents/pt/c/423722/. Acesso em: 25 Agos. 2016.

FAO/ONU. Food and Agriculture Organization of the United Nations. Food balance sheet of fish and fishery products in live weight and fish contribution to protein supply. Disponível em: <ftp://ftp.fao.org/FI/STAT/summary/FBS_bycontinent.pdf> acessado em: 27/11/2016.

FARIA, R. H. S.; MORISTER, M.; SORANNA, M. R. G. S.; SALLUM, W. B. CODEVASF - Companhia de Desenvolvimento dos Vales São Francisco e do Parnaíba. Manual de criação de peixes em viveiros. Org. ed: Anaí Nabuco/Lettera Comunicação, Brasilia - DF, 2013, 132 p.

GRAÇA, W. J. \& C. S. PAVANELLI. Peixes da planície de inundação do alto Rio Paraná e áreas adjacentes. Maringá, EDUEM. 2007, 308p

HASHIMOTO, D.T.; SENHORINI, J.A.; FORESTI, F.; PORTO-FORESTI, F. Interspecific fish hybrids in Brazil: management of genetic resources for sustainable use. Reviews in Aquaculture. v.4, p.108 - 118, 2012.

IBGE. Produção da Pecuária Municipal - 2015. Disponível em: <http://www.ibge.gov.br/home/estatistica/economia/ppm/2013/> Acesso em: 25 Agos. 2016.

IMEA, Agricultura e Pecuária do Estado de Mato Grosso. Diagnóstico da Piscicultura em Mato Grosso. - Instituto Mato-Grossense de Economia Agropecuária (Imea) - Cuiabá: 2014. 
KUBITZA, F. Nutrição e alimentação de tilápias-parte I. Panorama da Aquicultura, v. 2 , n. 52 , p. $42-50,1998$.

KUBITZA, F. Tanques-rede, rações e impacto ambiental. Revista Panorama da Aqüicultura, Rio de Janeiro-RJ, v. 9, n. 51, p. 44-50, 1999.

KUBITZA, F. Tilápia: tecnologia e planejamento na produção comercial. 2. ed; Jundiaí: 2011. 316p.

LEIRA, M. H.; CUNHA, L. T.; BRAZ, M. S.; MELO, C. C. V.; BOTELHO, H. A.; REGHIM, L. S. Qualidade da água e seu uso em Pisciculturas. PUBVET, v. 11, n.1, p.11-17, Jan/ 2017.

LIMA, A. F.; SILVA, A. P. RODRIGUES, A. P.O.; BERGAMIN, G. T.; TORATI, L. S.; PEDROZA, M. X. MACIEL, P.O. Qualidade da Água - Piscicultura Familiar. EMBRAPA, 2013. 8p.

MACEDO, C. F.; SIPAÚBA-TAVARES, L. H. Eutrofização e qualidade da água na piscicultura: consequências e recomendações. Boletim Instituto de Pesca, v. 36, n. 2, p. 149-163, 2010.

MARCO, K.; DALLACORT, R. JUNIOR, S. S.; JÚNIOR, C. A. F.; SILVA, E. S. Aptidão Agroclimática do Feijoeiro-Comum às Regiões Produtoras do Estado de Mato Grosso (Agroclimatic Aptitude of Common-Bean in Producing Regions of the Mato Grosso State). Revista Brasileira de Geografia Fisica, v. 7, n. 3, p. 558-571, 2014.

MELO, L.A. S.; IZEL, A. C. U.; RODRIGUES, F. M. Criação de tambaqui (Colossoma macropomum) em viveiros de argila/ barragens no Estado do Amazonas. Manaus: Embrapa-CPAA, 2001. 30p.

OSTRENSKY, A.; BOEGER, W. Piscicultura: fundamentos e técnica de manejo. Guaíba: Editora Agropecuária, 1998, 211p.

PESSOA, N. O. Avaliação Cinética do Sêmen de Pirapitinga (Piaractus brachypomus) Congelado Meio à Base de Água de Coco em Pó (acp-104®) ou Ringer em Três Meios de Ativação, 2009, 40 f. Dissertação (Programa de PósGraduação em Ciências Veterinárias), Universidade Estadual do Ceará Pró-Reitoria de Pós-Graduação e Pesquisa Faculdade de Veterinária, Fortaleza-CE, 2009.

PORTO-FORESTI, F.; HASHIMOTO, D. T.; PRADO, F. D.; SENHORINI, J. A.; FORESTI, F. A hibridação interespecífica em peixes. Panorama da Aquicultura, Laranjeiras, v. 21, n.126, p.28-33, 2011.

SAMPAIO, F. G.; LOSEKANN, M. E. LUIZ, A. J. B.; NEVES, M. C.; FRASCÁSCORVO, C. M. D.; RODRIGUES, G. S. Monitoramento e gestão ambiental da piscicultura em tanques-rede em reservatórios. Informe Agropecuário, Belo Horizonte, v. 34, n. 272, p. 1-11, 2013. 
SANTOS, L.; FILHO, M. P.; SOBREIRA, C.; ITUASSÚ, D.; FONSECA, F. A. L. Exigência protéica de juvenis de tambaqui (Colossoma macropomum) após privação alimentar. Acta Amazônica, v. 40, p. 597-604, 2010.

SIDONIO, S.; CAVALCANTI, I.; CAPANEMA, L.; MORCH, R. MAGALHÃES, G.; LIMA, J.; BURNS, V. JÚNIOR, A. J. A.; MUNGIOLI, R. Panorama da aquicultura no Brasil: desafios e oportunidades. BNDES Setorial, v. 35, p. 421-463, 2012.

SILVA, J. J.; PERIS, W. L. R.; SILVA, J. G.; SOUZA, D. F.; MOI, P. C. P. Avaliação do custo da produção da piscicultura no assentamento Nossa Senhora Aparecida em Várzea Grande Mato Grosso. Revista de administração e negócios da Amazônia, v.8, p. 39-54, 2016.

SOUZA, R. A .L.; MELO, J. S. C.; PEREIRA, J. A.; PERET, A. C. Determinação da densidade de estocagem de alevinos de tambaqui Colossoma macropomum Cuvier, 1818 (Pisces; Characidae) no Estado do Pará - Brasil. Boletim Técnico do CEPTA, v.11, p.39- 48, 1998.

TAVARES, L. H. S. Uso racional da água em aquicultura. UNESP - Jaboticabal. 2013.

VÀLQUEZ-TORRES, W. A Pirapitinga: reprodução e cultivo. In: BALDISSEROTTO, B.; GOMES, L. C. Espécies natives para piscicultura no Brasil. Santa Maria: Editora UFMS, p.203-224, 2005. 